\title{
WHAT'S VALUED MOST? SIMILARITIES AND DIFFERENCES BETWEEN THE ORGANIZATIONAL VALUES OF THE PUBLIC AND PRIVATE SECTOR
}

\author{
ZEGER VAN DER WAL, GJALT DE GRAAF AND KARIN LASTHUIZEN
}

In recent administrative and organizational literature much attention has been paid to values that guide organizational and managerial behaviour in the public and private domain. Comparative empirical research efforts, however, are sparse. This article reports the results of a comparative empirical survey of 382 managers from a variety of public and private sector organizations in The Netherlands. Contrary to much recent literature that presupposes the intermixing or convergence of value systems guiding governance in different kinds of organizations, the results of this study show two distinct and relatively classical value systems for government and business as well as a 'common core' of important organizational qualities. These are accountability, expertise, reliability, efficiency and effectiveness, all of which are considered crucial in both public and private sector organizations. Additional analysis shows that value preferences are primarily attached to sector rather than to age, gender, working experience, or previous employment in the other sector.

\section{INTRODUCTION}

Many administrative scholars claim that government and business organizational values 'should' be different, but whether they really are different merits further empirical analysis. Despite the rapidly expanding number of studies on values in public and private settings in recent decades, efforts to empirically study the differences and similarities between both sectors' values have been rare; most research is monosectoral and monodisciplinary in both theory and method. Although a lively debate has been initiated on the relationship between market and public values and the (un)desirability of value intermixing, most contributions are ideological rather than descriptive. We contribute to this debate empirically by comparing value orientations in public and private sector organizations, drawing upon theories and concepts from both public and business administration.

Realizing that research on ethics and values has a rich tradition in philosophy, sociology and political science (see, for example, Kluckhohn 1951; Rawls 1971; Rokeach 1973; Gaus 1990), the focus here is the recent administrative debate (public and private) on organizational values. Within both domains, several research perspectives can be distinguished with regard to values in an organizational context. Business administration scholars (particularly business ethicists) have studied organizational values in relation to organizational culture and climate (Schein 1992; Paine 1994, 2002), excellence and success (Peters and Waterman 2005) and, more recently, corporate social responsibility and corporate social performance (Agle and Caldwell 1999; Joyner and Payne 2002; Hemingway and Maclagan 2004), and workplace spirituality (Jurkiewicz and Giacolone 2004).

Within public administration, particularly administrative ethics, recent debates are dominated by the relationship between work values - 'pay,' 'job security' and 'stimulating

Zeger van der Wal is Post-doctoral Researcher, Gjalt de Graaf is Assist ant Professor and Karin Lasthuizen is Senior Researcher in Integrity of Governance, Department of Public Administration and Organization Science, VU University Amsterdam. 
work' - and public service motivation (Karl and Sutton 1998; Lewis and Frank 2002; Frank and Lewis 2004; Lyons et al. 2006), and the (assumed) influence of business-like approaches to government such as New Public Management (Hood 1991), performanceoriented organizational management (Pollitt and Bouckaert 2000) or management by measurement (Noordegraaf and Abma 2003) on traditional public sector organizational values such as 'impartiality,' 'lawfulness' and 'neutrality' (see, for example, Frederickson 1997, 2005; Lane 1994; Eikenberry and Kluver 2004).

The assumed influence of business-like approaches on public sector values is a recurrent and contested issue among public administration scholars and practitioners. A number of authors fear a decline in public service values (for example, Frederickson 1997, 2005; Lane 1994), arguing that overemphasis on business administration values comes at the expense of the unique value set that is necessary to serve the public interest (Maesschalck 2004). Some authors thus advocate a clear set of public service values (for example, Van Wart 1998; Beck Jørgensen 1999) and others have responded to this call (for example, Kernaghan 2000, 2003).

Discussions on problematic aspects of value intermixing, deal almost exclusively with the concern that the blurring of sectoral lines implies an increased appeal to market values in the public sector. According to Schultz (2004, p. 292) the reverse is also true: 'Although many would laud the move to encourage corporate social responsibility and ethical behavior, the intermixing of public and private functions raises vexing ethical questions similar to those when governmental and nonprofit entities intermix. The result may be that no clear set of ethical rules dominates'. This way of thinking harks back to Jane Jacob's (1992, p. xii) advocacy for a clear distinction between the public sector ethos ('guardian moral syndrome') and the private sector ethos ('commercial moral syndrome'): '[B]ehavior that (randomly) picks and chooses precepts from both syndromes creates monstrous moral hybrids; you can't mix up such contradictory moral syndromes without opening up moral abysses and producing all kinds of functional messes'.

At first glance, it seems evident that both corporate social responsibility (CSR) and new public management (NPM) developments would increase the likelihood of traditional public and private sector values intermixing or converging. Within the private sector, CSR emphasizes traditional public sector values such as sustainability, (social) responsibility, accountability and, specifically related to corporate integrity, 'empathy', 'solidarity', 'reliability' and 'fairness' (Kaptein and Wempe 2002, pp. 237-46). Within the public sector, NPM advocates traditional business values such as 'efficiency', 'effectiveness', 'innovation', 'profit', 'competence' and 'quality' (see Lane 1994; Tait 1997).

The prescriptions of both CSR and NPM enlarge the relevance of comparative empirical research on values in public and private settings and give rise to some interesting questions. Is it still possible (and relevant) to distinguish between two traditionally different value orientations? Will a comparison result in fragmented or even contradictory pictures? Or is one specific set of values predominant in each sector? We answer these questions by comparing the central organizational values deemed most important by 231 top-level federal civil servants and 151 business executives of medium- and large-sized companies in The Netherlands In identical questionnaires, respondents were asked to rank the most important values from a mixed set of 20 public sector, private sector and common core organizational values that were derived through reviews of literature (see Van der Wal et al. 2006).

Following this state-of-the-art literature review in public and private sector value research, we pay specific attention to the meaning and ontology of the main research 
concepts, and a set of values is presented as a survey research tool. A discussion of methodology and measures follows, together with the results of the study. We then discuss the results and present implications for future research.

\section{THE EXISTING RESEARCH ON PUBLIC AND PRIVATE SECTOR VALUES}

There is a widely recognized and rapidly growing body of empirical research on organizational core values for public sector organizations and employees (see, for example, Schmidt and Posner 1986; Kernaghan 1994, 2003; Goss 2003; Vrangbæk 2006; Beck Jørgensen 2006; Beck Jørgensen and Bozeman 2007) and private sector organizations and employees (see, for example, Agle and Caldwell 1999; Posner and Schmidt 1984, 1993; Hemingway and Maclagan 2004; Watson et al. 2004). Surprisingly, empirical 'comparative' research that offers a reliable picture of the prominence of the values in both the public and the private sector is lacking.

As has been said, contradictory views exist among scholars on the differences, similarities and relationship between organizational values in public and private realms. Many emphasize differences and in most cases consider value intermixing to be problematic and undesirable (see, for example, Jacobs 1992; Lane 1994; Frederickson 1997, 2005; Schultz 2004). Others, however, emphasize similarities and stress that the same moral criteria and values can (or even should) be applied to all kinds of organizations (see, for example, Kaptein 1998; Caiden 1999).

In discussions about the differences between government and business, normative arguments prevail. Statements on what government and business values are (not) and should (not) be are intertwined; it is a debate with an ideological twist (see Noordegraaf and Abma 2003, p. 857). Although 'structural' and 'managerial' differences between public and private sector organizations have been extensively addressed (Allison 1979; Ross 1988; Coursey and Bozeman 1990; Boyne 2002), comparative studies on 'ethical' differences between the sectors are sparse. A relatively small number of empirical studies have addressed issues such as 'ethical climate' (Solomon 1986; Wittmer and Coursey 1996) and 'ethical management' (Berman and West 1994) in a comparative setting. The few comparative empirical studies on values that exist, predominantly apply concepts and propositions from the fields of psychology and sociology (Posner and Schmidt 1996; Stackman et al. 2006; Lyons et al. 2006), rather than from public administration and business administration theory. They therefore contribute relatively thinly to an accumulative body of 'administrative' knowledge on values. Moreover, these studies have a strong individual (employee or managerial) motivational focus, rather than an organizational one.

That another problematic aspect of value research in public and private settings is which specific values belong to which types of organizations and sectors is not disputed. Scholars sometimes all too easily attribute certain values to the realm of 'either' government 'or' business. For example, within the NPM debate, values are classified as 'old' or 'traditional' on one hand, and 'new' or 'emerging' on the other (see, for example, Lane 1994; Tait 1997; Kernaghan 2000, 2003). Van den Heuvel et al. (2002), conclude in their empirical study on public sector values in The Netherlands that 'efficiency' is an NPM value, as opposed to those characterized as Weberian, whereas Weber himself $(1926,1972)$ mentioned 'efficiency' as a crucial bureaucratic virtue. A similar confusion surrounds the value 'effectiveness'. Is the measurement of output and outcome a typical private sector technique (one which is increasingly applied within governmental organizations) or do public sector organizations traditionally focus on outcome rather than aspects of cost-effectiveness or 'efficiency'? In this context, the results of a survey on values among 
public sector executives by Schmidt and Posner 1986 are particularly interesting. In their study, public managers attributed considerably higher scores to 'effectiveness,' 'reputation' and 'efficiency' than to 'service to the public' (1986, p. 448). Moreover, the data were collected in 1982, and thus before the beginning of the NPM-era. Clearly, the empirical results mentioned are far from being consonant and do not render a clear picture of what it is that is valued most in each sector.

It thus seems arbitrary to attribute specific values to specific sectors and organizations solely on conceptual or theoretical grounds. And it is precisely this that seems to turn the highly relevant debate on 'changing public sector values' (Van Wart 1998) into a fragmented and sometimes rather unsatisfying clash of ideological stances. The results of this study will enable an empirical attribution of key organizational values to public and private sector organizations, determining which values are associated with which sector. It is, however, imperative to first address the ontology and meaning of the concept of value, and define specific values.

\section{CENTRAL RESEARCH CONCEPTS}

A problem often mentioned by organizational ethics scholars is the continuing disagreement on defining and measuring values (see Schmidt and Posner, 1986, p. 448). This has led to a 'values literature confusion' (Agle and Caldwell 1999, pp. 327-8). According to Connor and Becker (1994), this confusion is a result of the constant use of different instruments and concepts, making it almost impossible to accumulate a coherent body of knowledge. Inconsistencies in the definitions of the concept of value - and in the distinctions between value and related constructs such as attitude, belief and norm - appear in the literature (Wiener 1988); values are in fact 'essentially contested concepts' (de Graaf 2003 , p. 22). Moreover, it has been shown that in many studies on organizational values a proper definition is not presented at all (see Van der Wal et al. 2006). To avoid further confusion, we pay specific attention to the concept of organizational values.

Despite the conceptual confusion and the different ontological attributions to the value construct, broad agreement exists on the fact that values cannot actually be seen or heard, and can only be observed in the ways in which they manifest themselves through attitudes, preferences, decision making and action (see Kluckhohn 1951; Rokeach 1973; Beyer 1981; Schmidt and Posner 1986). In the words of Schmidt and Posner (1986, p. 448), '[T]hey are so deep-seated that we never actually "see" values themselves. What we "see" are the ways in which people's values manifest themselves: in opinions, attitudes, preferences, fears, and so on'. The best we can say is that values never come just by themselves, never appear unaccompanied. Values are always attached to a value manifestation, a choice of action such as a decision-making preference, and express a quality or general standard of conduct.

In our questionnaire, 'values' were therefore defined as 'important qualities and standards that have a certain weight in the choice of action' (see de Graaf 2003, p. 22; Van der Wal et al. 2006). Values refer to those things that are most important to a person or an organization. They are broader and more general than norms, which are 'regulations prescribing what the proper conduct in certain situations is'. 'Morality', then, denotes 'values and norms taken together'. And ethics can be defined as the 'systematic reflection on morality' (Van der Wal et al. 2006).

The focus here is on 'shared organizational values'. It has been convincingly argued in the literature that organizations have their own specific set of values encoded in their culture (see, for example, Deal and Kennedy 1982; Schein 1992). It has also been argued 
that part of the enculturation process of employees involves abandoning individual morals and values as the basis of ethical judgement and replacing them with an organizationally based collective ethic (Jackall 1988). Many authors also argue that institutions have goals, values and knowledge that exist independent of their constituents, and which determine, in large part, the decisions and behaviour of people inside those institutions (see, for example, French 1984; Pruzan 2001; de Graaf 2005). In other words, organizations have their own dynamic (de Graaf 2003, 2005). Although such a perspective implies that an organizational culture is not a static construct, and is in part constructed and recoded by individuals entering the organization (see Schein 1992), the focus of this study concerns those values that dominate the present decision-making practices of the organization. To clarify, the important and related a priori question on the values and motivations of individuals related to a preference for employment in the public or private sector (Karl and Sutton 1998; Lewis and Frank 2002; Frank and Lewis 2004; Lyons et al. 2006) is not addressed here.

The internal dynamic within organizations render methodological individualism hard to defend. The former transcend individual behaviour and decisions. Although individual subjects are included in this study, the unit of analysis will be 'organizational values', the values that play a role in organizational decision making. In this context, executive managers are perceived to be spokespersons for their organizations and overseers of strategic decision-making processes.

\section{Set of values as a research tool}

Our research presented a mixed set of 20 values and their definitions to the respondents. The process by which the set of values used in this research were constructed has been described extensively in a previous study (Van der Wal et al. 2006). Through an extensive literature review of both administrative and business ethics literature (recent books, journals, codes of conduct and government documents), over 500 different values were deduced. These were subsequently clustered, integrated and weighed using 15 variables that determined the relevance and importance of the specific value. For instance, values that were explicitly characterized as organizational and very relevant to the specific sector were determined to be more important than values that were mentioned without an organizational or sectoral specification.

For both government and business, 13 organizational values were determined to be the most important. Five values were present in both sets, and the remaining 21 were again weighed, integrated and supplemented by empirical research results, so that a definitive set of 20 values, suitable for survey research, could be created (Van der Wal et al. 2006). In short, the mixed set of values (table 1) includes what some call 'moral values' - such as honesty - as well as what some call 'instrumental values' - such as efficiency. Here, such an explicit distinction is not applied, subsequent to the argument that proclaiming 'efficiency' as a leading organizational principle is as much a moral choice as it is an instrumental one.

The value set is an attempt to create a feasible value survey research tool. The set consists of a balanced mix between characteristic public sector values ('impartiality', 'lawfulness', 'social justice'), private sector or business values ('innovativeness', 'profitability', 'self-fulfillment'), values mentioned in both administrative and business ethics literature and research, and public and private sector codes of conduct ('accountability', 'expertise', 'honesty', '(social) responsibility' and 'transparency'). Clear definitions were attached to the 20 organizational values. These definitions were drawn from the literature in 
TABLE 1 Mixed set of public, private and common core organizational values

Organizational value set

Accountability: act willingly to justify and explain actions to the relevant stakeholders

Collegiality: act loyally and show solidarity towards colleagues

Dedication: act with diligence, enthusiasm and perseverance

Effectiveness: act to achieve the desired results

Efficiency: act to achieve results with minimal means

Expertise: act with competence, skill and knowledge

Honesty: act truthfully and comply with promises

Impartiality: act without prejudice or bias toward specific group interests

Incorruptibility: act without prejudice and bias toward private interests

Innovativeness: act with initiative and creativity (to invent or introduce new policies or products)

Lawfulness: act in accordance with existing laws and rules

Obedience: act in compliance with the instructions and policies (of superiors and the organization)

Profitability: act to achieve gain (financial or other)

Reliability: act in a trustworthy and consistent way towards relevant stakeholders

Responsiveness: act in accordance with the preferences of citizens and customers

Self-fulfillment: act to stimulate the (professional) development and well-being of employees

Serviceability: act helpfully and offer quality and service towards citizens and customers

Social justice: act out of commitment to a just society

Sustainability: act out of commitment to nature and the environment

Transparency: act openly, visibly and controllably

accordance with our definition of the main construct, to reduce the effect of individual respondent perception and interpretation. This aspect is of particular importance in research on values - as has been argued in the section on central research concepts. De Vries (2002), for instance, has shown convincingly that civil servants within different administrative cultures interpret a seemingly universal concept such as 'honesty' very differently.

According to Schmidt and Posner 1986, p. 448), '[R]esponses to a questionnaire may not correspond exactly with how people behave; questionnaire responses are likely to be more positive and idealistic than behavioural responses which occur when managers feel under pressure, confronted with conflicting information and competing loyalties'. There is, however, a need for basic empirical data on public and private sector value differences and a survey enables a broad picture of different organizations in both sectors to emerge. Because the objective is to study the perception of the importance of values, a selfcompletion survey seems the appropriate method. Some respondents remarked that filling in the questionnaire had been a clarifying values exercise for themselves and the organization.

\section{METHODOLOGY AND MEASURES}

\section{Participants}

A 7-page self-completion mail survey was sent to 766 managers of government organizations (response rate 30.16 per cent) and 497 managers of business organizations (response rate 30.44 per cent). This was felt to be a respectable response rate given the type of respondent. It is also comparable with earlier published mail surveys among top managers, albeit somewhat lower than most public sector response rates and considerably higher than most business response rates (see Posner and Schmidt 1984, 1993, 1996; Bowman and Williams 1997; Kim 2001; Goss 2003). The questionnaire was first pre-tested among 16 public and private sector managers. The questionnaire was then distributed in 
co-operation with the relevant professional associations: Senior Public Service (in Dutch: ABD) and the Dutch Centre of Executive and Non-executive Directors (in Dutch: NCD). ABD is the professional association of the top management group of the Dutch federal government; its database consists of almost 800 heads of directorates, departments and agencies that automatically become members when they reach a certain hierarchical and salary level. NCD is a professional association of 4,500 executives and non-executive board members of various small, medium and large companies (mostly finance consultancy, industry, law and infrastructure). Membership of NCD is voluntary.

All ABD members were surveyed. From the NCD members, 500 managers were chosen at random: 400 managers of companies with at least 50 but less than 1,000 employees and 100 managers of companies with at least 1000 employees. This particular sampling of NCD members was to achieve the best comparability with the ABD members. ABD members ranged from bureau chiefs supervising a few dozen employees to department heads supervising up to 30,000 employees. Although organizational and departmental size sometimes varied widely, limiting the sample to top management helped to control for a number of other variables (education, income and general socioeconomic status), which may confound value differences (see Lyons et al. 2006). With regard to gender and age, the sample closely resembled the demographic of the population at large (see table 2). The final sample consisted of 382 managers.

\section{Measures}

The survey contained questions on organizational values as well as on characteristics of the organization and management. Respondents were obliged to select the most important 'actual' values from the set: 'Please rank those five values that are most important when decisions are made within the organization in order of importance'. In addition, respondents were asked to rank those five values that 'should be' most important in order of importance, so that a certain degree of distinction between fact and norm could be ensured (see Lawton 1998). It was explicitly stated that the respondents were supposed

TABLE 2 Respondent characteristics (population if available is given between brackets)

\begin{tabular}{|c|c|c|}
\hline & Public sector $(n=231)(\%)$ & Private sector $(n=151)(\%)$ \\
\hline \multicolumn{3}{|l|}{ Age: } \\
\hline $26-35$ & $0[1]$ & $1[3]$ \\
\hline $36-45$ & 20 [19] & 17 [18] \\
\hline $46-55$ & $55[51]$ & 41 [37] \\
\hline 56 and older & 25 [29] & $41[31]$ \\
\hline \multicolumn{3}{|l|}{ Gender: } \\
\hline M: & $85[85]$ & 97 [94] \\
\hline F: & 15 [15] & $3[6]$ \\
\hline \multicolumn{3}{|l|}{ Number of employees supervised: } \\
\hline$<100$ & 56 & 36 \\
\hline $100-500$ & 27 & 27 \\
\hline$>500$ & 17 & 37 \\
\hline \multicolumn{3}{|l|}{ Working at present organization: } \\
\hline$<1$ year & 6 & 4 \\
\hline $1-5$ years & 31 & 24 \\
\hline $5-10$ years & 9 & 17 \\
\hline$>10$ years & 54 & 55 \\
\hline Average number of employees entire organization: & $\mathrm{N} / \mathrm{A}$ & 4259 \\
\hline Has worked in other sector: & 33 & 29 \\
\hline
\end{tabular}


to rank those values that were considered 'most important when decisions are being made within the unit or organization that you supervise', emphasizing values that guide organizational decision making, instead of individual moral opinions of the manager themselves.

The scores of the rankings were recoded into reverse scores to be weighed correctly ( 5 = most important; 1 = least important of the top five) and the frequency (number of respondents that places this value 'within' the top five), mean (based on the ranking of the value 'within' the top five) and standard deviation of each value were calculated. Then a sum of scores $\left(\sum\right)$ was created, based upon frequency as well as rank ( $\mathrm{N} x$ mean) and, in addition, a standardized share $\left(\sum / N\right)$ was computed to enable a comparison of values between the two sectors and to observe the importance of specific values.

To characterize the extent to which the participating organizations could be characterized as public or private, questions were asked on three traditionally distinctive features of public and private sector organizations: organizational funding, public authority and control, and organizational tasks (see Dahl and Lindblom 1953; Perry and Rainey 1988; Scott and Falcone 1998; Rainey and Bozeman 2000). Factor analysis (PCA with varimax rotation) showed that the three variables loaded on one factor $\left(\mathrm{R}^{2}=90\right.$ per cent and factor loadings between .93 and .97) and reliability analysis ensured that a reliable scale could be built ( $\alpha=$. 95). A new variable, 'publicness', was computed with scores between 1 (core private) and 4 (core public).

To be able to answer the question of which values significantly correlated with the type of organization, indicated by publicness as predictor variable, multivariate regression analyses were performed for each value as dependent variable, in which gender, age, years of employment and previous working experience in the other sector, served as control variables.

\section{RESULTS}

Table 3 shows the main results for the public and private sector actual values. The sum of scores presents the most detailed attribution of scores to the 'actual' values in both sectors, including both frequency and mean. A standardized share $\left(\sum / N\right)$ was computed to create a clear distinction between more and less important values and enable a comparison of values between the two sectors.

\section{Public sector: most and least important actual values}

According to public sector executives, 'accountability' ('act willingly to justify and explain actions to the relevant stakeholders') is the most important value in public sector decision making, followed by 'lawfulness', 'incorruptibility', 'expertise', 'reliability', 'effectiveness', and 'impartiality'. Notable is the relatively low position of 'obedience' (17th). It might well be that 'obedience' is too strong a term, associated with blindly 'following the leader'. Loyalty (to the political superiors) as a value might have been ranked substantively higher. 'Self-fulfillment' and 'profitability' are the relatively least important public sector values: only two public executives mention 'profitability' as an important 'actual' public sector value.

\section{Private sector: most and least important actual values}

The classical 'profitability' ('act to achieve gain (financial or other)') is the most important value in business decisions, followed by 'accountability', 'reliability', 'effectiveness', 'expertise' and 'efficiency'. Notable is the relatively low position of 'serviceability' (14th), 
TABLE 3 Descriptive statistics for actual values in the public and private sector in order of importance (most prominent in bold)

\begin{tabular}{|c|c|c|c|c|c|}
\hline Values & $\mathbf{N}$ & Mean & SD & $\Sigma$ & $\begin{array}{l}\text { Stand. } \\
\text { Sh. }\left(\sum / N\right)\end{array}$ \\
\hline \multicolumn{6}{|l|}{ Public sector $(n=231)$} \\
\hline Accountability & 125 & 3.30 & 1.52 & 413 & 1.8 \\
\hline Lawfulness & 123 & 3.35 & 1.41 & 412 & 1.8 \\
\hline Incorruptibility & 104 & 3.45 & 1.31 & 359 & 1.6 \\
\hline Expertise & 110 & 3.15 & 1.39 & 346 & 1.5 \\
\hline Reliability & 101 & 2.90 & 1.24 & 293 & 1.3 \\
\hline Effectiveness & 92 & 3.05 & 1.46 & 281 & 1.2 \\
\hline Impartiality & 74 & 2.97 & 1.33 & 220 & 1.0 \\
\hline Efficiency & 63 & 2.86 & 1.33 & 180 & 0.8 \\
\hline Transparency & 64 & 2.47 & 1.32 & 158 & 0.7 \\
\hline Serviceability & 47 & 2.72 & 1.51 & 128 & 0.6 \\
\hline Dedication & 41 & 2.61 & 1.46 & 107 & 0.5 \\
\hline Collegiality & 37 & 2.59 & 1.40 & 96 & 0.4 \\
\hline Honesty & 32 & 2.72 & 1.40 & 83 & 0.4 \\
\hline Innovativeness & 23 & 2.74 & 1.42 & 67 & 0.3 \\
\hline Responsiveness & 21 & 2.33 & 1.35 & 49 & 0.2 \\
\hline Sustainability & 16 & 2.81 & 1.56 & 45 & 0.2 \\
\hline Obedience & 13 & 2.77 & 1.36 & 36 & 0.2 \\
\hline Social justice & 15 & 2.40 & 1.45 & 36 & 0.2 \\
\hline Self-fulfillment & 12 & 2.58 & 1.08 & 31 & 0.1 \\
\hline Profitability & 2 & 2.50 & 0.71 & 5 & 0.0 \\
\hline \multicolumn{6}{|c|}{ Private sector $(n=151)$} \\
\hline Profitability & 75 & 3.40 & 1.58 & 255 & 1.7 \\
\hline Accountability & 66 & 3.12 & 1.54 & 206 & 1.4 \\
\hline Reliability & 70 & 2.86 & 1.48 & 200 & 1.3 \\
\hline Effectiveness & 58 & 3.31 & 1.40 & 192 & 1.3 \\
\hline Expertise & 60 & 3.15 & 1.19 & 189 & 1.3 \\
\hline Efficiency & 48 & 3.13 & 1.45 & 150 & 1.0 \\
\hline Honesty & 39 & 3.23 & 1.33 & 126 & 0.8 \\
\hline Innovativeness & 47 & 2.45 & 1.14 & 115 & 0.8 \\
\hline Incorruptibility & 34 & 3.18 & 1.42 & 108 & 0.7 \\
\hline Dedication & 30 & 3.13 & 1.31 & 94 & 0.6 \\
\hline Lawfulness & 29 & 3.14 & 1.38 & 91 & 0.6 \\
\hline Transparency & 35 & 2.34 & 1.28 & 82 & 0.5 \\
\hline Collegiality & 25 & 2.88 & 1.30 & 72 & 0.5 \\
\hline Serviceability & 20 & 2.75 & 1.29 & 55 & 0.4 \\
\hline Responsiveness & 13 & 3.15 & 1.52 & 41 & 0.3 \\
\hline Sustainability & 21 & 1.90 & 1.00 & 40 & 0.3 \\
\hline Impartiality & 11 & 3.18 & 1.40 & 35 & 0.2 \\
\hline Obedience & 6 & 2.83 & 1.47 & 17 & 0.1 \\
\hline Social justice & 5 & 3.40 & 1.52 & 17 & 0.1 \\
\hline Self-fulfillment & 8 & 1.88 & 1.13 & 15 & 0.1 \\
\hline
\end{tabular}

a value that is closely related to classical business principles such as 'customer-friendliness' and 'customer-orientation'. 'Obedience', 'social justice' and 'self-fulfillment' are the relatively least important private sector values.

\section{Public and private sector actual values: differences and similarities}

Clear traditional differences exist between both rankings. 'Lawfulness', 'impartiality' and 'incorruptibility' were considered most important public sector values and were absent from the business top values. 'Profitability' and 'innovativeness' were present in the top of the business values and absent from the public sector top values. 'Profitability' according to this measure could even be considered the least important public sector value. 
There are, however, many similarities. Four of the most important values, 'accountability', 'expertise', 'reliability' and 'effectiveness' appear in both sectors. These four values can be considered to be the common core of shared organizational values. Nevertheless, 'expertise' and, especially, 'accountability' are considered more important in the public sector (share 1.5 and 1.8 respectively) than in the private sector (share 1.4 and 1.3 respectively). In addition, when it comes to less important or relatively unimportant values, the similarities by far exceed the differences: 'responsiveness', 'obedience', 'self-fulfillment', 'social justice' and 'sustainability' are ranked as relatively unimportant in both sectors.

\section{The effect of publicness and other confounding variables}

Table 4 shows the main results from the multivariate regression analysis for the actual values. This analysis enables us to find out which values are correlated with the type of sector. Which values, in other words, belong more specifically to either the private or the public sector, and what is the influence of confounding variables such as gender and age of the respondent, years of employment, and previous working experience in the other sector. These variables may have been of influence, since previous studies have shown that younger civil servants place significantly more importance on self-enhancement (career) work values than older civil servants (Lyons et al. 2005), although work values are probably more influenced by individual preferences than organizational values. Other studies (for example, Rainey and Bozeman 2000) have pointed to the significance of organizational characteristics such as size, structure and culture as determinants of differences rather than sector as such.

As can be seen in table 4, publicness correlates with six out of 20 values. This means that the distinction between public and private was important for the way the values were ranked: 'profitability', 'innovativeness' and 'honesty' are clear private sector values

TABLE 4 Multiple regression analysis for the public $(n=231)$ and private sector $(n=151)$

\begin{tabular}{|c|c|c|c|c|c|c|}
\hline Value & $\mathbf{R}^{2}$ & Publicness & Gender & Age & $\begin{array}{l}\text { Years of } \\
\text { employment }\end{array}$ & $\begin{array}{l}\text { Past } \\
\text { employment }\end{array}$ \\
\hline Accountability & .014 & & & & & \\
\hline Expertise & .000 & & & & & \\
\hline Reliability & .000 & & & & & \\
\hline Effectiveness & .000 & & & & & \\
\hline Efficiency & .003 & & & & & \\
\hline Profitability & .316 & $-.552^{* *}$ & & & & \\
\hline Innovativeness & .054 & $-.233^{* *}$ & & & & \\
\hline Honesty & .024 & $-.154^{*}$ & & & & \\
\hline Lawfulness & .121 & $.384^{* *}$ & & & & \\
\hline Incorruptibility & .050 & $.223^{* *}$ & & & & \\
\hline Impartiality & .040 & $.200^{* *}$ & & & & \\
\hline Transparency & .034 & & & & & $-.179 * *$ \\
\hline Dedication & .005 & & & & & \\
\hline Collegiality & .001 & & & & & \\
\hline Serviceability & .004 & & & & & \\
\hline Responsiveness & .000 & & & & & \\
\hline Sustainability & .004 & & & & & \\
\hline Obedience & .001 & & & & & \\
\hline Social justice & .005 & & & & & \\
\hline Self-fulfillment & .006 & & & & & \\
\hline
\end{tabular}

Note 1: Only significant beta's are reported with * $p<.01, * * p<.001$.

Note 2: The importance of the values in bold is significantly predicted by the publicness of the organization to which the respondent belongs. 
and 'lawfulness', 'impartiality' and 'incorruptibility' are clear public sector values. Publicness proved not to be decisive for the other 14 values: factors that are outside the reach of this study may explain their rankings. With the exception of transparency, the confounding variables showed no correlation with the values. This is in line with the organizational focus of this study. After all, differences in gender, age, and so on, were not supposed to be of significant influence since the managers who participated were asked not to display personal moral preferences but instead to portray their organization. From the additional analysis it can be concluded that 'innovativeness' and 'honesty' clearly are private sector values and that 'efficiency' should be considered as a common core value. This result coincides beautifully with the results from the standardized share and enables us to create a caesura by 0.8 , which separates the most important public and private sector values from the less important ones. Reaffirmed by the regression analysis, eight prominent values can now be distinguished for both sectors.

\section{Actual and 'should be' values}

Table 5 shows the top ten values that 'should be' most important for both sectors. Overall, the differences between the actual and the desired situation are small. Of the values that appear to be most important in the desired situation in the public sector, 10 out of 10 are identical to the actual situation. For the business sector, the score is 9 out of 10 . A closer look at individual questionnaires, using a basic subtraction exercise between fact and norm, revealed that the extremely marginal differences between fact and norm were not due to 'survey respondent acquiescence' (see Fowler 2002), which would have been the case if a majority of the respondents had simply selected identical values in both parts of the questionnaire out of time constraints. The few differences are there, however, are interesting: according to public sector managers, 'effectiveness' should be much more important in decision-making situations (2nd in the 'should be' rankings and 6th in the actual situation). 'Impartiality', a classical government value, should be of much more importance in the business sector (7th in the 'should be' rankings and 17th in the actual rankings!). This congruence between the actual and desired situation might imply that most managers consider the values that are deemed important in organizational decision making to be either ideal or self-evident.

\section{DISCUSSION AND CONCLUSIONS}

This study asked at the outset whether it was still possible and relevant to distinguish between two traditionally different value orientations. On the whole, the results of this

TABLE 5 'Should be' public and private sector values

\begin{tabular}{lc}
\hline Public sector & Private sector \\
\hline 1. Accountability & 1. Profitability \\
2. Effectiveness & 2. Accountability \\
3. Incorruptibility & 3. Expertise \\
4. Reliability & 4. Reliability \\
5. Lawfulness & 5. Effectiveness \\
6. Expertise & 6. Honesty \\
7. Efficiency & 7. Impartiality \\
8. Transparency & 8. Efficiency \\
9. Impartiality & 9. Innovativeness \\
10. Serviceability & 10. Incorruptibility \\
\hline
\end{tabular}


study suggest that the answer is yes. However, looking closely at the results, the answer is also no. There are a few classical as well as unexpected differences, but there are also a number of strong similarities between the values of government and business.

\section{Public sector values}

The results of the study show a traditional and consistent value pattern for both the public and private sector. The most important actual public sector values - 'accountability', 'lawfulness', 'incorruptibility', 'expertise', 'reliability', 'effectiveness', 'impartiality', and 'efficiency' - are consistent with often mentioned crucial public sector values in the administrative ethics and business ethics literature (for example, Kaptein and Wempe 2002, pp. 237-46; Kernaghan 2003, p. 712), in Dutch public sector codes of conduct (Ethicon 2003) and in earlier research among civil servants (Van den Heuvel et al. 2002); 'integrity', however, is often used as a specific value instead of the closely related 'incorruptibility' (see Van der Wal et al. 2006).

The same goes for strongly related values such as 'transparency' ('openness') and 'reliability' ('trustworthiness'). 'New' or 'emerging' values (Kernaghan 2000, 2003), such as 'innovation' and 'profitability', traditionally associated with the private sector, are not present in the most important actual public sector organizational values. 'Effectiveness', however, is among the most important values for government organizations. As stated above, the conceptual status of this value in the literature is not clear (see Schmidt and Posner 1986; Kernaghan 2000, 2003). Interestingly, 'effectiveness' is mentioned as the second most important 'should be' value by public sector managers, a result that suggests that top level civil servants, at least in The Netherlands, perceive the public sector as less effective than it should be - and perhaps could be. It could also point to a certain degree of desirability for a more businesslike organizational structure and culture, in line with NPM influences. This claim is supported by the higher ranking of 'efficiency' and 'transparency' in the 'should be' situation than in the actual situation. Overall, however, our results do not lend support to the claim that classical public service values are devaluated or degraded by the emergence of classical business sector values.

It is also interesting to see what is valued least. 'Serviceability' and 'responsiveness' are ranked 10th (in both situations) and 15th (13th in the 'should be' situation) respectively. The fact that these values are not perceived to be among the most important after a decade of public management reforms in Western countries, in which outwardoriented, socially responsive, and citizen- and customer-friendly public management styles and structures have been promoted and institutionalized, is surprising. It might be that these values are not yet as important as the classical public sector traits of 'lawfulness' and 'expertise', although the number one value, 'accountability', is related to outwardly and responsive conduct. Another explanation is simply that public organizations do not practice what they preach, or rather: do not preach what they practice. A final note on this result is that it might have substantially differed if we had surveyed public servants who operate in direct customer contact, rather than managers as decisionmaking overseers.

'Self-fulfillment' and 'profitability' are ranked least important in the value set (see Van den Heuvel et al. 2002). This does not mean that they are not at all important or that decisions do not involve these values, but that they are seldom mentioned among the five most important organizational values in governmental decision making. Also worth mentioning is the surprisingly relatively low rank of 'collegiality' (12th) and 'obedience' (17th). 


\section{Private sector values}

The highest ranking private sector values - 'profitability', 'accountability', 'reliability', 'effectiveness', 'expertise', 'efficiency', 'honesty', and 'innovativeness' - also approximate crucial private sector values that are mentioned in the administrative ethics and business ethics literature (see Posner and Schmidt 1993, 1996; Lane 1995, p. 195; Kernaghan 2000, 2003). This is not the case for those values most often mentioned in the codes of conduct of multinationals (see Kaptein 2004, p. 22), something which is probably due to the cultural differences between the companies studied, resulting in a fragmented list of international code of conduct business values.

Remarkably, 'serviceability', a value that expresses acting helpfully and providing high quality (and is thus strongly related to customer-friendliness and customer-orientation), was ranked relatively low (14th). Apparently, the concept of 'service' in the private sector is not as important in organizational decision making as one might believe when observing general business (marketing) discourse. Alternatively, this value is not associated with an orientation towards customers and quality management by business managers (although it was clearly defined as such in the questionnaire). Also remarkable is the relatively low ranking of 'self-fulfillment' (20th), a dominant 'buzzword' in corporate job advertisements until a few years ago ('This job is about developing yourself and realizing your life goals', 'Become what you want to become' and so on).

An explanation for the low ranking of 'serviceability' and 'self-fulfillment' could be that attention to the social (or soft) aspects of business life has declined due to corporate scandals, tighter legislation for businesses, and a more short-term focus on shareholder growth over recent years. The same seems to hold for CSR-related values, such as 'sustainability' and 'social justice', which are both low in the private sector rankings. Another explanation is again that 'deeds do not match words' or vice versa: social and sustainable policies have become increasingly important, but are not yet anchored or internalized within private sector value patterns. The high ranking of 'accountability' might also be explained by corporate scandals and tighter regulations. One business manager pointed out in a handwritten comment that accountability in a business context also embodies the ability to demonstrate effectiveness of policy decisions.

Paradoxically, 'impartiality' - a classical civil servant virtue and arguably a business person's vice - is ranked high as a 'should be' value by business managers. This could have something to do with the corporate scandals of recent years, in which business leaders were criticized for being too partisan in their relations with politicians, accountants, and consultants. Another interpretation is that (partly due to a heightened awareness caused by these same scandals), this points to a private sector desire to treat employees more fairly and equally.

\section{Similarities and differences: traditional distinctiveness, convergence or intermixing?}

The important question is: which values are truly valued most and which values can be considered to be public, private or common core? The standardized share was used as a means to determine which qualities and standards are valued most, and the regression analysis determined which values were public, private and common core, as was argued in the section above. Based on this measure, figure 1 displays a graphical distribution of the core organizational values between both sectors.

As discussed above, the results of this study do not lend support to the often-assumed hypothesis that a decline of traditional public sector values is taking place in the today's public sector environment due to the adoption of businesslike values (see, for example, 


\section{PRIVATE SECTOR VALUES}

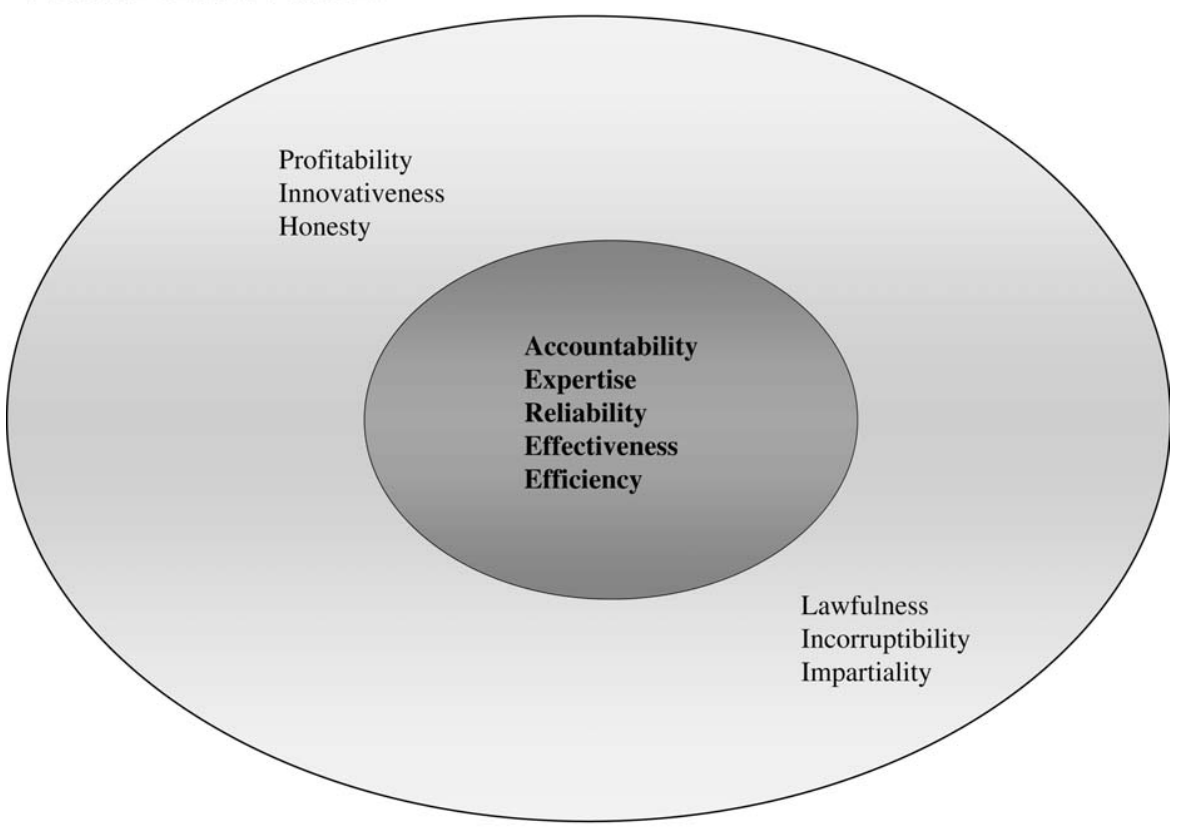

PUBLIC SECTOR VALUES

FIGURE 1 Value layers with a public and private pole and a common core of shared organizational qualities and standards

Frederickson 1997, 2005; Kernaghan 2000, 2003; Maesschalck 2004); nor do they support statements on the key importance of 'sustainability' and 'social justice' in modern business life as a result of CSR developments, although 'accountability' and 'reliability' are considered extremely important by business managers (see Kaptein and Wempe 2002, pp. 237-46). The 'predominance hypothesis', which states that one set of values is becoming predominant in all organizations (Schulz 2004), is not supported either. The specific differences found in our study are too fundamental.

On one hand, traditional public sector organizational values, such as 'impartiality', are not among the most important private sector organizational values, and traditional private sector values such as 'profitability' and 'innovativeness' are not among the most important public sector values. These three values especially are strongly related to and predicted by the specific sectors. On the other hand, 'effectiveness' is among the most important actual public sector organizational values and emerges as a 'should be' value; in the business sector, the same goes for 'impartiality'. Moreover, a number of common core values, 'accountability', 'efficiency', 'expertise', 'reliability' and 'effectiveness', were distinguished, as well as a number of common less important values, 'responsiveness', 'obedience', 'self-fulfillment', 'social justice' and 'sustainability'.

Nevertheless, it is hard to determine, based on the data, whether these commonalities point to convergence or intermixing between public and private sector organizational value patterns. An interesting question is whether those common core values identified have always been shared by organizations in the different sectors, or if value patterns are indeed intermixing or converging between the sectors. To observe such fundamental value shifts, it is imperative that longitudinal research among a closed group of respondents be conducted. 
The results of the study align with those of Posner and Schmidt (1996, p. 277) who, while pointing to specific areas of agreement, state that the values of business and federal government executives are more different than alike. An interesting point of discussion raised by these authors is whether the differences and similarities are related mostly to organizational or individual differences, and to what extent 'people with certain values and perspectives join the public sector purposely (in order to actualize certain values) rather than the private sector' (Posner and Schmidt 1996, p. 287).

A few interesting exceptions aside, it is clear that sector, specified and operationalized as publicness, is a strong predictor and determinant of value preferences within organizational decision making. The question then is whether sector determines managerial and organizational value preferences, or if managers prefer a career in a certain sector in the first place to achieve congruence between personal and organizational values (see Posner and Schmidt 1993). Such an individual focus goes beyond the reach of this study, but future research efforts could focus more on the relation between personal values and career deliberations, the debate on PSM, and organizational values and culture.

\section{Limitations of this study and directions for future research}

Elements of social desirability and perhaps coincidence are inherently related to the type of measurement used in this study. However, the same problems might arise when respondents are asked to rate values or select the most important of two or more values, for instance, in a dilemma scenario. Attributing specific values to specific conduct through participatory observation (see Beck Jørgensen 2006) or simulation has been tried relatively few times and has to be explored more systematically. The same goes for other qualitative instruments, such as case studies on the relation between policy decisions, organizational behaviour, codes of conduct and mission statements, and in-depth interviews, on what is truly valued most when important decisions are made, to improve our understanding of the nature and causes of sectoral differences and the context in which differences are constructed and experienced. By focusing more on context we might be able to obtain more insight into whether an increasingly popular value in both domains, such as accountability, relates to the output accountability, associated with annual business reports and shareholder meetings, or to process accountability, associated with the lawfulness of government acting, laws and procedures (see Jos and Tompkins 2004). In Koppel's (2005) words: 'What are the different pathologies of a concept such as accountability?'

Finally, it should also be noted that the validity and generalizability of the results of this study are limited to the public and private sector in The Netherlands. International comparative research is necessary to reveal whether differences and similarities exist between, for instance, the public and private sectors in Western European or Westminster countries. Such a comparison might be worthwhile because these countries are similar in a number of important aspects (see Kernaghan 2003) and because values and ethics are strongly related to cultural traditions and preferences, making it difficult to compare very different and remote cultures and societies. Using the set of values in table 1 as a survey research tool enables valid and consistent comparisons to be made.

\section{REFERENCES}

Agle, B.R. and C.B. Caldwell. 1999. 'Understanding Research on Values in Business', Business and Society, 38, 3, $326-87$.

Allison, G. 1979 [1992]. 'Public and Private Management: Are They Fundamentally Alike in All Unimportant Aspects?', in J. Shafritz and A. Hyde (eds), Classics of Public Administration. Belmont, CA: Wadsworth.

Beck Jørgensen, T.B. 1999. 'The Public Secor in an In-between Time: Searching for New Public Values', Public Administration, $77,3,565-84$. 
Beck Jørgensen, T.B. 2006. 'Public Values, their Nature, Stability and Change. The Case of Denmark', Public Administration Quarterly, 30, 4, 365-98.

Beck Jørgensen, T.B. and B. Bozeman. 2007. 'The Public Values Universe: An Inventory', Administration and Society, 39, 3, $354-81$.

Berman, E. and J. West. 1994. 'Ethics Management in Municipal Governments and Large Firms: Exploring Similarities and Differences', Administration and Society, 26, 2, 185-203.

Beyer, J.M. 1981. 'Ideologies, Values, and Decision Making in Organizations', in P.C. Nystrom and W.H. Starbuck (eds), Handbook of Organizational Design. New York: Oxford University Press, pp. 166-202.

Bowman, J.S. and R.L. Williams. 1997. 'Ethics in Government. From a Winter of Despair to a Spring of Hope', Public Administration Review, 57, 6, 517-26.

Boyne, G.A. 2002. 'Public and Private Management: What's the Difference?', Journal of Management Studies, 39, 1, 97-122.

Caiden, G.E. 1999. 'The Essence of Public Service Ethics and Professionalism', in L.W.J.C. Huberts and J.H.J. van den Heuvel (eds), Integrity at the Public-Private Interface. Maastricht: Shaker, pp. 21-44.

Connor, P. and B. Becker. 1994. 'Personal Values and Management: What Do We Know and Why Don't We Know More?', Journal of Management Inquiry, 3, 1, 67-73.

Coursey, D. and B. Bozeman. 1990. 'Decision Making in Public and Private Organizations: A Test of Alternative Concepts of "Publicness"', Public Administration Review, 50, 5, 525-35.

Dahl, R.A. and C.E. Lindblom. 1953. Politics, Economics and Welfare. New York: Harper.

Deal, T. and A.A. Kennedy. 1982. Corporate Cultures: the Rites of and Rituals of Corporate Life. Reading, MA: Addison Wesley.

Eikenberry, A.M. and J.D. Kluver. 2004. 'The Marketization of the Nonprofit Sector: Civil Society at Risk?', Public Administration Review, 64, 2, 132-40.

Ethicon. 2003. Gedragscodes binnen Overheidsinstellingen [Codes of Conduct within Governmental Organizations] (http://www. ovia.nl/dossiers/intoverheid/codeoverheidsinstellingenverslag.ppt).

Fowler, F.J. 2002. Survey Research Methods, 3rd edn. London: Sage.

Frank, S.A. and G.B. Lewis. 2004. 'Government Employees: Working Hard or Hardly Working?', American Review of Public Administration, 34, 1, 36-51.

Frederickson, H.G. 1997. The Spirit of Public Administration. San Francisco, CA: Jossey-Bass.

Frederickson, H.G. 2005. 'Public Ethics and the New Managerialism: an Axiomatic Theory', in H.G. Frederickson and R.K. Ghere (eds), Ethics in Public Management. New York: M.E. Sharpe, pp. 165-83.

French, P.A. 1984. Collective and Corporate Responsibility. New York: Columbia University Press.

Gaus, G.F. 1990. Value and Justification. New York: Cambridge University Press.

Goss, R.P. 2003. 'What Ethical Conduct Expectations Do Legislators Have for the Career Bureaucracy?', Public Integrity, 5, 2, 93-112.

Graaf, de, G. 2003. Tractable Morality. Customer Discourses of Bankers, Veterinarians and Charity Workers. Rotterdam: ERIM.

Graaf, de, G. 2005. 'Tractable Morality', Journal of Business Ethics, 60 1, 1-15.

Hemingway, C.A. and P.W. Maclagan. 2004. 'Managers' Personal Values as Drivers of Corporate Social Responsibility', Journal of Business Ethics, 50, 1, 33-44.

Hood, C.C. 1991. 'A Public Management for all Seasons?' Public Administration, 69, 1, 3-20.

Jackall, R. 1988. Moral Mazes. The World of Corporate Managers. New York: Oxford University Press.

Jacobs, J. 1992. Systems of Survival. A Dialogue on the Moral Foundations of Commerce and Politics. New York: Random House.

Jos, P.H. and M.E. Tompkins. 2004. 'The Accountability Paradox in an Age of Reinvention. The Perennial Problem of Preserving Character and Judgment', Administration and Society, 36, 3, 255-81.

Joyner, B. and D. Payne (2002). 'Evolution and implementation: a study of values, business ethics and corporate social responsibility.' Journal of Business Ethics 41, 4, 297-311.

Jurkiewicz, C.L. and R.A. Giacolone. 2004. 'A Values Framework for Measuring the Impact of Workplace Spirituality on Organizational Performance', Journal of Business Ethics, 49, 129-42.

Kaptein, M. 1998. Ethics Management. Auditing and Developing the Ethical Content of Organizations. Issues in Business Ethics. Dordrecht: Kluwer.

Kaptein, M. 2004. 'Business Codes of Multinational Firms: What Do They Say?', Journal of Business Ethics, 50, 1, $13-31$.

Kaptein, M. and J. Wempe. 2002. The Balanced Company. A Theory of Corporate Integrity. Oxford: Oxford University Press.

Karl, K.A. and C.L. Sutton. 1998. 'Job Values in Today's Work Force: A Comparison of Public and Private Sector Employees', Public Personnel Management, 22, 3, 515-27.

Kernaghan, K. 1994. 'The Emerging Public Service Culture: Values, Ethics, and Reforms', Canadian Public Administration, 37, 4, 614-30.

Kernaghan, K. 2000. 'The Post-bureaucratic Organization and Public Service Values', International Review of Administrative Sciences, 66, 91-104.

Kernaghan, K. 2003. 'Integrating Values into Public Service: The Values Statement as Centerpiece', Public Administration Review, $63,6,711-19$. 
Kim, H.S. 2001. 'Structure and Ethics Attitudes of Public Officials', Public Integrity, 3, 4, 69-86.

Kluckhohn, C. 1951. 'Values and Value-Orientations in the Theory of Action', in T. Parsons and E.A. Shils (eds), Toward a General Theory of Action. Theoretical Foundations for the Social Sciences. New York: Harper and Row, pp. 388-433.

Koppell, J.G.S. 2005. 'Pathologies of Accountability: ICANN and the Challenge of Multiple Accountabilities Disorder', Public Administration Review, 65, 1, 94-108.

Lane, J.E. 1994. 'Will Public Management Drive Out Public Administration?', Asian Journal of Public Administration, 16, 2, 139-51.

Lawton, A. 1998. Ethical Management for the Public Services. Buckingham: Open University Press.

Lewis, G.R. and S.A. Frank. 2002. 'Who Wants to Work for the Government?', Public Administration Review, 62, 4, 395-404.

Lyons, S.T., L.E. Duxbury and C.A. Higgins. 2005. 'Is the Public Service Ethic in Decline?', Paper presented at the Ninth International Research Symposium on Public Management (IRSPM IX), 6-8 April, Bocconi University, Milan, Italy.

Lyons, S.T., L.E. Duxbury and C.A. Higgins. 2006. 'A Comparison of the Values and Commitment of Private Sector, Public Sector, and Parapublic Sector Employees', Public Administration Review, 66, 4, 605-18.

Maesschalck, J. 2004. 'The Impact of the New Public Management Reforms on Public Servants' Ethics: Towards a Theory', Public Administration, 82, 2, 465-89.

Noordegraaf, M. and T. Abma. 2003. 'Management by Measurement? Public Management Practices Amidst Ambiguity', Public Administration, 81, 4, 853-71.

Paine, L.S. 1994. 'Managing for Organizational Integrity', Harvard Business Review, 72, 107-117.

Paine, L.S. 2002. Value Shift: Why Companies must merge Social and Financial Imperatives to achieve Superior Performance. New York: McGraw-Hill.

Perry, J.L. and H.G. Rainey. 1988. 'The Public-Private Distinction in Organization Theory: A Critique and Research Strategy', The Academy of Management Review, 13, 2, 182-201.

Peters, T.J. and R.H. Waterman. 2005. In Search for Excellence: Lessons from America's Best Run Companies. New York: Harper Row.

Pollitt, C. and G. Bouckaert. 2000. Public Management Reform: A Comparative Analysis. Oxford: Oxford University Press.

Posner, B.Z. and W.H. Schmidt. 1984. 'Values and the American Manager: An Update', California Management Review, 26, 3, $202-16$.

Posner, B.Z. and W.H. Schmidt. 1993. 'Value Congruence and Differences Between the Interplay of Personal and Organizational Value Systems', Journal of Business Ethics, 12, 2, 341-7.

Posner, B.Z. and W.H. Schmidt. 1996. 'The Values of Business and Federal Government Executives: More Different Than Alike', Public Personnel Management, 25, 3, 277-89.

Pruzan, P. 2001. 'The Question of Organizational Consciousness: Can Organizations have Values, Virtues and Visions?', Journal of Business Ethics, 29, 3, 271-84.

Rainey, H.G. and B. Bozeman. 2000. 'Comparing Public and Private Organizations: Empirical Research and the Power of the $A$ Priori', Journal of Public Administration Research and Theory, 10, 447-69.

Rawls, J. 1971. A Theory of Justice. Cambridge, MA: Harvard University Press.

Rokeach, M. 1973. The Nature of Human Values. New York: The Free Press.

Ross, B.H. 1988. 'Public and Private Sectors - The Underlying Differences', Management Review, 77, 5, $28-33$.

Scott P.G. and S. Falcone. 1998. 'Comparing Public and Private Organizations. An Explanatory Analysis of Three Frameworks', American Review of Public Administration, 28, 2, 126-45.

Schein, E.H. 1992. Organizational Culture and Leadership, 2nd edn. San Francisco, CA: Jossey-Bass.

Schmidt, W.H. and B.Z. Posner. 1986. 'Values and Expectations of Federal Service Executives', Public Administration Review, 46, $4,447-54$.

Schultz, D. 2004. 'Professional Ethics in a Postmodern Society', Public Integrity, 6, 4, 279-97.

Solomon, E.E. 1986. 'Private and Public Sector Managers: an Empirical Investigation of Job Characteristics and Organizational Climate', Journal of Applied Psychology, 71, 2, 247-59.

Stackman, R.W., P.E. Connor and B.W. Becker. 2006. 'Sectoral Ethos: A Comparison of the Personal Values Systems of Female and Male Managers in the Public and Private Sectors', Journal of Public Administration Research and Theory, 16, 4, 577-97.

Tait, J. 1997. 'A Strong Foundation: Report of the Task Force on Public Service Values and Ethics (A Summary)', Canadian Public Administration, 40, 1-22.

Van den Heuvel, J.H.J., L.W.J.C. Huberts and S. Verberk. 2002. Het morele gezicht van de overheid. Waarden, normen en beleid [The Moral Face of Government. Values, Norms and Policy]. Utrecht: Lemma.

Van der Wal, Z., L.W.J.C. Huberts, J.H.J. van den Heuvel and E.W. Kolthoff. 2006. 'Central Values of Government and Business: Differences, Similarities and Conflicts', Public Administration Quarterly, 30, 3, 314-64.

Van Wart, M. 1998. Changing Public Sector Values. New York: Garland.

Vrangbæk, K. 2006. 'Public Sector Values in Denmark. Results from a Survey of Public Managers', Paper presented at the Annual EGPA Conference, 6-9 September, Bocconi University, Milan, Italy.

Vries, M. de. 2002. 'Can you Afford Honesty', Administration and Society, 34, 3, 309-34.

Watson, G.W., S.D. Papamarcos, B.T. Teague and C. Bean. 2004. 'Exploring the Dynamics of Business Values: A Self-Affirmation Perspective', Journal of Business Ethics, 49, 4, 337-46. 
Weber, M. 1926. Politik als beruf. Berlin: Duncker and Humblot.

Weber, M. 1972. Gezag en Bureaucratie [Authority and Bureaucracy]. Rotterdam: University Press Rotterdam.

Wiener, Y. 1988 'Forms of Value Systems: A Focus on Organizational Effectiveness and Cultural Change and Maintenance', The Academy of Management Review, 13, 4, 534-45.

Wittmer, D. and D. Coursey. 1996. 'Ethical Work Climates: Comparing Top Managers in Public and Private Organizations', Journal of Public Administration Research and Theory, 6, 4, 559-71.

Date received 13 October 2006. Date accepted 25 January 2007. 
Copyright of Public Administration is the property of Blackwell Publishing Limited and its content may not be copied or emailed to multiple sites or posted to a listserv without the copyright holder's express written permission. However, users may print, download, or email articles for individual use. 